\title{
Social-Psychological-Health Predictors of Fondness of Arkenstone among Indonesians
}

\author{
Tommy Prayoga and Juneman Abraham* \\ Faculty of Humanities, Psychology Department, Bina Nusantara University, Jakarta, Indonesia
}

\begin{abstract}
Arkenstone fever is a phenomenon of a sudden boost of interest among many Indonesians towards the stones during 2014-2015. Accessories were equipped with them, minerals were hunt, and the economic for the small and medium-sized enterprises were expanded. In this study, we seek to determine and explain the underlying social psychological factors behind this trend. In 2015, we gathered 100 participants $\left(M_{\text {age }}=22.61\right.$ years old, $S D_{\text {age }}=3.818$ years) living in Jakarta, the capital of Indonesia and possessing at least one arkenstone to examine their Aesthetic Style, Illusory Belief, Health Belief, and Connectedness to Nature to arrange a theoretical model explaining the Fondness of arkenstone. Using path analysis, we found out that Aesthetic Style primarily predicts the Fondness of arkenstone. Connectedness to Nature and Illusory Belief were found out to be able to predict Aesthetic Style, and finally, participant's Health Belief can predict their Illusory Belief. Overall, the theoretical model formed from these findings can be integrated into a model.
\end{abstract}

Keywords: Arkenstone; Agate; Illusory belief; Health belief; Aesthetic style; Connectedness with nature

\section{Introduction}

During 2014-2015, Indonesia experienced the fever of arkenstone. This emerging fondness of arkenstone, or agate, ("batuk akik" in Indonesian) among people is indicated by a growing population of stone hunters, stone smiths and mostly, people who accessorize their fingers with colorful arkenstone on rings. This trend hits Indonesian like a tidal wave, as it affects not only ordinary citizens but also government officials; from Minister of Manpower, Hanif Dhakiri-who collects arkenstones and view them as part of national culture [1] to Minister of Social Affairs, Khofifah Indar Parawansa who stated arkenstone craftsmen/stone smiths as one of the new occupation in East Java and considered it to be effective in reducing the number of divorce in the area [2]. The arkenstone itself, known as 'agate' in geological terms, is a mineral structure consisting of various components of hard and colorful silicon layers [3]. As the popularity of the mineral among people raised so is the price. Depending on various aspects such as size, pattern, color, texture and origins, the price may vary from a few hundred thousand to millions of rupiah.

However, there are yet any studies conducted to investigate the cause of this 'fever'. All we know from the news, articles and the increasing number of arkenstone trader is that people buy, collect and admire them for many purposes. This sudden trend has also left us puzzled, as this is similar to the flowerhorn fish trend back in the early 2000s where many people started to breed them for good luck and prosperity. This is the first article, to our knowledge, to ever investigate the psychosocial aspects underlying the arkenstone trends among Indonesian by outlining a few possible social-psychological factors that might have caused the trend. We propose that individual's Aesthetic Style, Health Beliefs, Illusory Belief, and Connectedness to Nature play roles in determining the favoring of arkenstone.

\section{Aesthetic Style}

One possible reason for attraction towards arkenstone might be its aesthetic value. Its beautiful pattern and design are the qualities that attract people into collecting, hunting and taking care of the arkenstone as collections and accessories. How people perceive a product to be aesthetically beautiful might influence their attitude on the product. As Chen put it in his analysis of web design, aesthetic can influence brand perception and credibility in purchasing decision [4]. According to Louis Kattsoff [5], aesthetic is the knowledge of the beauty and the art of beauty. As John Hospers stated, it is related with the contemplation of art, by analyzing concepts in the deep reflection [5]. This contemplation makes people understand and perceive better towards the art, opening the opportunity to admire and appreciate it as a unique product and thus making the art a valuable possession of luxury.

Godey et al. [6] suggested that the consumption of a product or brand depends on the aesthetic perception or 'style' of the customer. Thus the value and luxury perceived may vary among products and individuals. If a product's perceived aesthetic value match individual's personal aesthetic standard, they will be more positively inclined towards it. In turn, one acts upon this positive inclination, resulting in collecting, taking care of, and invest on the stone. Therefore, we hypothesized, "One's aesthetic style can predict his/her fondness of arkenstone" (H1) (Figure 1).

\section{Illusory/magical Belief}

Illusory/magical beliefs might play a role in explaining the fondness of arkenstone. As some people believe in the power of healing, others believe that the stones bring luck, prosperity and fortune. Some people believe that some arkenstones are guarded and protected by out of this world forces; some people call it magic [7]. According to Einstein et al.

*Corresponding author: Juneman Abraham, Faculty of Humanities, Psychology Department, Bina Nusantara University, Jakarta, Indonesia, Tel: (62-21) 5345830; E-mail: juneman@binus.ac.id

Received February 18, 2016; Accepted June 22, 2016; Published June 28, 2016

Citation: Prayoga T, Abraham J (2016) Social-Psychological-Health Predictors of Fondness of Arkenstone among Indonesians. Abnorm Behav Psychol 2: 116. doi:10.4172/2472-0496.1000116

Copyright: @ 2016 Prayoga T, et al. This is an open-access article distributed under the terms of the Creative Commons Attribution License, which permits unrestricted use, distribution, and reproduction in any medium, provided the original author and source are credited. 


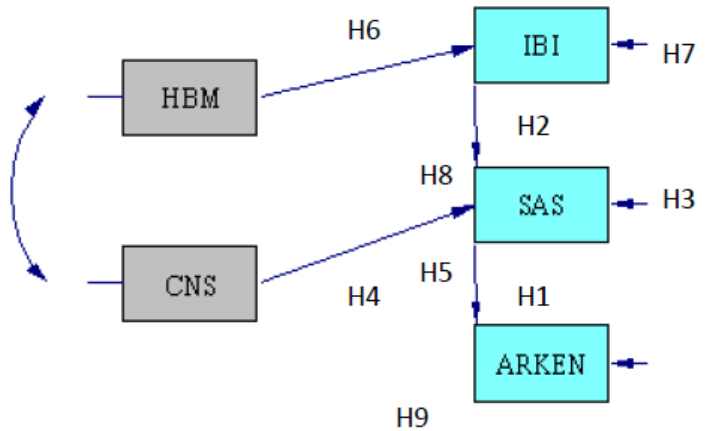

Notes: HBM=Health Belief; CNS=Connectedness to Nature; $|\mathrm{B}|=\mid$ llusory/ magical Belief; SAS=Aesthetic Style; ARKEN=Fondness to arkenstone.

Figure 1: Hypothetical model.

[8] this kind of belief is not based on the scientific and empirical base and thus categorized as a magical belief.

Kingdon et al. [9] stated that magical beliefs usually involve superstitious belief, paranormal phenomenon, and religious belief. Usually in the modern era, this kind of belief are forcing its way into people's belief by disguising in empirical and scientific paradigms [10], often attributing them to objects and practice. This type of belief emerges in the presence of mysterious or obscure objects, such as arkenstone. Gestalt [11] psychology suggests that the obscurity of the object increases the aesthetic attractiveness due to its hidden quality inviting people to inspect or get to know it [12]. Thus, the higher individual's belief in illusion or magical subjects, the higher chance they will admire the subjects from their personal aesthetical standard and viewpoint. Therefore, we hypothesized, "One's illusory/magical belief can predict his/her aesthetic style" (H2).

In turn, the Aesthetic Style tendency mediates the relationship between the Illusory/magical Belief and Fondness of arkenstone, suggesting that individuals with high magical beliefs might be fond of arkenstone, due to the mystery in its beauty. We hypothesized, "Aesthetic style mediates the relationship between illusory/magical belief and fondness of arkenstone among individuals with arkenstones" (H3).

\section{Connectedness with Nature}

The fact that the majority of arkenstone in the market is mined in Indonesia might be one underlying factor of attraction towards it. As mentioned above, even the Minister of Manpower himself views the arkenstone as the inseparable part of Indonesia's nature and cultural heritage. This glorification and pride towards the product of Mother Nature are representations of people's connectedness with nature. In Eastern Culture, especially Indonesia, spiritual practices, behaviors and rituals involving nature have always been important aspects of traditions for many occasions; for example, the practice of Tri Angga among Balinese that emphasizes on keeping the balance between human and nature in daily activities [13]. It dictates that as a human living in nature, we ought to respect and care for it as nature sustaining human activities and ties.

Connectedness with nature can be defined as a self-perceived relationship of interconnection between the self and the natural world; it reflects a sensation of kinship and an individual's affective experience of connection with nature (Mayer and Frantz; Schultz, Shriver, Tabanico, and Khazian; as cited in [14]. It has been proposed as a universal phenomenon concerning the relation between one's self- image and nature based on a basophilic disposition (Mayer, Frantz, Bruehlman-Senecal, and Dolliver; Schultz et al.; as cited in [14].

Brady [15] discussed that in Carlson's Nature Appreciation Model, appreciation towards nature is related with aesthetic appreciation. The perceptual stimulus preceding any information combined with already known cultural knowledge would purify away the richness of aesthetic experience. The key is that for individual to appreciate-regardless of any scientific or supporting information-what nature has offered (in this case, the arkenstone), he/she needs to think of it as a beautiful, aesthetic object. Thus, people that feel they are connected more with natural surrounding will be more tend to understand and inspect object according to their aesthetic style, forming our hypothesis, "One's connectedness with nature can predict his/her aesthetic style" (H4). The possession of the stone, in turn, could provide the aesthetic experience for one to enjoy [15], making Aesthetic Style a bridging mediator between Connectedness to Nature and Fondness of arkenstone. We hypothesized, "Aesthetic Style mediates the relationship between connectedness with nature and fondness of arkenstone among individuals with arkenstones" (H5).

\section{Health Belief}

Many claims of arkenstone health benefits were made by the media and rumors [16]. People believe that wearing arkenstone balances the bodily processes and brings good health for the bearer. This practice is not unusual throughout the Eastern culture, as the natural mineral is said to possess healing power. For example, there are beliefs that coral stone heals infertility and circulations problem, Amethyst heals insomnia, and agate heals pain [17]. Despite the validity of this claim, the focus on this study is individual's belief of benefits obtained from this stone towards their health.

As Brunner et al. [18] stated, socioeconomic circumstances, living and working conditions and social and psychological factors are strong influences on well-being and health over the life course. Considering that these constructs are subject to major cultural and philosophical influences [18], there could be a different explanation for arkenstone fondness from the framework of social epidemiology as Indonesia is one of the Eastern countries with strong and diverse oriental influences. Standing from these premises, we proposed to explain this phenomenon in relations to arkenstone fondness from individual's health belief, because clearly the phenomenon of believing in healing power of the stones is a health concept that is not limited by physical and biological process [19], which means there are behavioral and psychological aspects underlying it.

One of the models explaining health beliefs is The Health Belief Model proposed by Rosenstock [20]. Rosenstock explained people's health belief using five constructs: (1) perceived severity, (2) perceived susceptibility, (3) cue for action, (4) perceived barriers, and (5) perceived outcomes and benefits [21]. Another is the Wellness Belief, which measures individual subjective perceptions of the biomedical, functional and well-being indicators of wellness [22]. Individuals that possess arkenstone and take them into account when considering their health-despite its lack of scientific evidence of health benefitsmight indicate that they have considerable belief in mystical or illusory occurrence. Thus, we hypothesized, "One's health belief can predict his/ her illusory/magical belief" (H6). In turn, the Illusory Belief acts as a mediator, bridging the relationship of Health Belief Prediction towards Aesthetic Style. This is because the object of health belief here is the 'unscientific' object that is appreciated for aesthetic reasoning as the framework of meaning. Thus, we hypothesized, "Illusory/magical 
Citation: Prayoga T, Abraham J (2016) Social-Psychological-Health Predictors of Fondness of Arkenstone among Indonesians. Abnorm Behav Psychol 2: 116. doi:10.4172/2472-0496.1000116

Page 3 of 5

belief mediates the relationship between health belief and aesthetic style, having effects on fondness of arkenstone, among individuals with arkenstone" (H7)

By those premises and hypothesis formed, we proposed that Illusory/magical Belief and Connectedness to Nature could together predict an individual with arkenstone's Aesthetic Style, and all prediction together could form a model explaining the Fondness of arkenstone. We formed the hypothesis, "Individual with arkenstone's illusory/magical belief and connectedness with nature can predict his/ her aesthetic style" (H8) and "The variables investigated in this study can form a model explaining fondness of arkenstone" (H9) (Figure 1).

\section{Method}

\section{Participants and design}

The participants in this study were adolescents and young adults aged 18-30 and lived in Jakarta, the capital of Indonesia. We recruited 100 participants $\left(M_{\text {age }}=22.61\right.$ years old, $S D_{\text {age }}=3.818$ years), 82 men and 18 women, all of whom having the basic knowledge and information of arkenstone, and possess at least an arkenstone in any form of accessories (rings, necklaces, bracelets). The sampling method employed was convenience sampling.

This study used the quantitative, correlational predictive design. The data were analyzed by using Path Analysis to determine regression coefficient of each variable, and their t-value.

\section{Instruments}

Health belief was measured using Health Belief Model Scale (HBMS) by Champion from the study by Jones et al. [20] in the context of food poisoning and Wellness Belief Scale (WBS) by Bishop et al. [22]. We integrated the dimension of perceived barriers and benefits of HBMS with the biomedical and well-being components of WBS in final adaptation result of 15 items. The Cronbach's Alpha (internal consistency reliability index) of this instrument is $\alpha=0.742$.

Aesthetic style was measured using Scale of Aesthetic Style (SAS) by Godey et al. [6]. They applied the measurement of aesthetic in consumer behavior with the purpose of measuring the consumer's experience with the aesthetic value of a product. Final adaptation for present study resulted in 10 items with Cronbach's Alpha, $\alpha=0.900$. Illusory/magical belief was measured using Illusory Belief Inventory (IBI) items measuring magical thinking by Kingdon et al. [9]. All 24 items were adapted into the present study with the Cronbach's Alpha, $\alpha=0.771$. Connectedness with nature was measured using Connectedness with Nature Scale (CNS) by Mayer and Franz [14]. Final adaptation of present study resulted in 13 items with Cronbach's
Alpha, $\alpha=0.791$.

Participant were asked to indicate their agreement towards each item's statement that might describe them by choosing among response options ranging from Strongly Disagree (very unsuitable in describing him/herself; score of 1) to Strongly Agree (very suitable in describing him/herself; score of 6). The fondness of arkenstone was measured by asking participants to indicate how much they like the arkenstone from a scale of 1 to 10 . The questionnaire also contains some questions regarding the reasons they are in the arkenstone trend for acquiring the qualitative responses.

\section{Results}

\section{Path analysis}

RMSEA indicates a value of $0.000(R M S E A<0.05)$, with $P$-value of 0.707 ( $P$-value $>0.05)$, of Chi-square $\left(\chi^{2}\right)=2.96$. They show that this model has a good fit and can be used to explain Fondness of arkenstone. Figure 2 is the diagram representation of the model resulting from path analysis.

Each prediction's path coefficient magnitude and $t$-value significance are determined using LISREL 8.8. For significance level at the 0.05 , we used $t=|1.96|$ as a critical value for judging statistical significance of the prediction results [23]. Analysis results of each prediction show that Aesthetic Style is able to predict Fondness of arkenstone $(\beta=0.05, t=2.32>1.96)$. Illusory/magical Belief $(\gamma=0.31$, $t=3.33>1.96)$ and Connectedness to Nature $(\gamma=0.48, t=3.52>1.96)$ are able to predict Aesthetic Style significantly. Health Belief can predict Illusory/magical Belief $(\gamma=0.48, t=3.99>1.96)$ significantly (see Equation 1 for knowing the regression equations and effect sizes or coefficients of determination, $R^{2}$ ). Thus $\mathrm{H} 1, \mathrm{H} 2, \mathrm{H} 4, \mathrm{H} 6$, and $\mathrm{H} 8$ were supported by the empirical data. Based on the goodness of fit indices, there are also indirect effects in the relationships. $\mathrm{H3}, \mathrm{H} 5, \mathrm{H}$, and $\mathrm{H} 9$ were supported by empirical data (Figure 2).

LISREL Estimates (Maximum Likelihood)

Structural Equations

$\mathrm{IBI}=0.48^{\star} \mathrm{HBM}$, Errorvar. $=92.58, \mathrm{R}^{2}=0.14$

(0.12) (13.29)

3.996 .96

$\mathrm{SAS}=0.31^{\star} \mathrm{IBI}+0.48^{\star} \mathrm{CNS}$, Errorvar. $=92.45, \mathrm{R}^{2}=0.21$

(0.094) (0.14) (13.27)

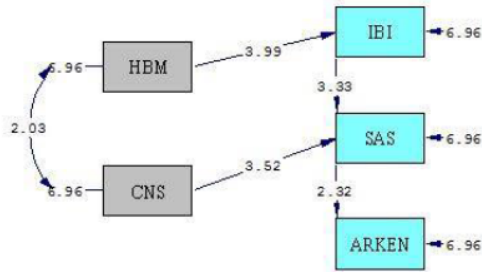

Chi-Square $=2.96, d f=5$, P-value $=0.70656$, RMSEA $=0.000$

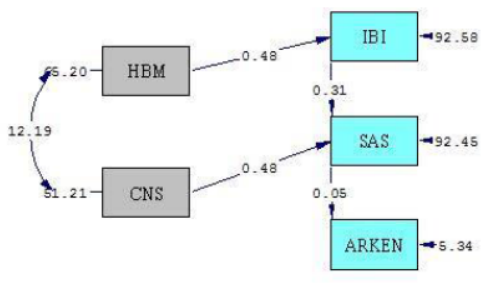

Chi-Square $=2.96, d f=5, P$-value $=0.70656$, RMSEA $=0.000$

Notes: HBM=Health Belief; CNS=Connectedness to Nature; IBI=Illusory/magical Belief; SAS=Aesthetic Style; ARKEN=Fondness to arkenstone.

Figure 2: Path analysis results: $t$-value (left) and coefficientestimation (right) 


\subsection{3 .526 .96}

ARKEN $=0.050^{\star}$ SAS, Errorvar. $=5.34, \mathrm{R}^{2}=0.052$

(0.022) (0.77)

\subsection{6 .96}

\section{Reduced Form Equations}

$\mathrm{IBI}=0.48^{\star} \mathrm{HBM}+0.0^{\star} \mathrm{CNS}$, Errorvar. $=92.58, \mathrm{R}^{2}=0.14$

SAS $=0.15^{\star} \mathrm{HBM}+0.48^{\star} \mathrm{CNS}$, Errorvar. $=101.59, \mathrm{R}^{2}=0.13$

$$
2.563 .52
$$

\section{$\mathrm{ARKEN}=0.0076^{\star} \mathrm{HBM}+0.024^{\star} \mathrm{CNS}$, Errorvar. $=5.60, \mathrm{R}^{2}=0.0068$}

$(0.0044)(0.013)$

\subsection{1 .94}

Notes: $\mathrm{HBM}=$ Health Belief; $\mathrm{CNS}=$ Connectedness to Nature; IBI=Illusory/magical Belief; SAS=Aesthetic Style; ARKEN=Fondness to arkenstone.

Equation 1: Path analysis results by LISREL: Regression equation.

\section{Discussion}

We found out that the main reason that individuals with arkenstone are fond of their possession is due to the stone's beauty appearance. According to the result, Aesthetic Style significantly predicts the tendency to like the stone. This means that individuals with arkenstone, as hypothesized, do align the beauty the stone has with their own beauty standard. Simply put, the stone was liked and admired because of the tendency to evaluate its aesthetic. As Brady [15] puts it, natural arts are able to provide of Aesthetic experience that interest people. However, there's more into this finding. The issue here is not about ordinary art, but rather, natural stones that are believed to be mystical, and could provide many purposes. This suggest that the stones' 'aesthetic' is not only a form of beauty that is simply to be admired. Rather, there are factors within the person who collects them that made those stone align with their aesthetic standard.

Aesthetic style in this study, as hypothesized, was influenced primarily by two factors. First, the Illusory/magical Belief predicting the tendency for the participants to refer to their own aesthetic style. This shows that mystical or conjunctive belief does, in fact, influence the tendency to judge an object aesthetically. This finding is not surprising especially in this study's demographic, as mystery and mystical stimulus present a sense of attractiveness for the object of desire [11]. Perceiving and believing something from a more illusive stance could draw individuals towards a more aesthetic presence [12] of the object, making them draw a conclusion from its physical and design attribute. Meanings and values attached to an aesthetic object can be lived in such a way by the recipient, which seems to actualize their minds and emotions. Simply put, "we act on our fantasies and our dreams" [24]. Thus, aesthetic style and magical belief are connected through the emotions that have a practical function namely expectations amplifier/ booster [25]. Agate stone lovers may be among the people who have certain expectations after seeing it (for example, from the carving) as something that symbolizes and rekindles imagination of the fulfillment of such expectations.
Second, Connectedness with Nature, as a sense of nature-self interconnection, reflects a certain amount of affective experience within the body [14]. Physical attractiveness, being one of the fundamental and primary stimuli of Aesthetic, could be influenced by the affective experience the natural surrounding provides. As the result suggest, it could propel an individual to be more inclined in perceiving them to be beautiful according to their 'style'. This is not surprising, because, for a long time, aesthetics is seen as "a mirror to nature" [26]. Within history-psychological dimension, aesthetics are the result of the evolution of the natural world, which are then transformed into human cognition [27]. History has provided or conditioned the knowledge necessary for human to form works/creations based on their view of nature and to appreciate the works/creations based on their admiration for the aesthetic qualities of nature. Natural environment and Aesthetic style are connected through harmony, elegance, unity, order and balance, as well as having a positive function as a framework meaning of human life experience. Perhaps agate lovers are those who appreciate the nature. This quality, in turn, strengthens the relationship between aesthetic style with a magical belief in their psyche.

The mediation effects of Aesthetic Style in the relationship between Connectedness with Nature-Fondness of arkenstone and Illusory Belief-Fondness of arkenstone provide a more in-depth explanation of arkenstone's beauty attraction. This shows that the beauty that individuals perceive in arkenstone stem from these two factorsmystical and natural sense. The illusory belief tendency provides a perception of mystery from the pattern of design that gives the arkenstone its sense of beauty. From a more natural perspective, the stone's natural origin might provide the sense of affective 'natural' experience that makes it beautiful.

Finally, the result that shows Health Belief predicts Illusory Belief in this context of research indicates that participant's beliefs of their health practices and knowledge influence their Illusory Belief. In a sense that how they regulate and view medical practices-scientific or not-increases their chances to believe in superstition, at least in the demographic of this study. The more they believe in their practices regarding health is right, the higher chances they will think conjunctively, combining and seeing connections between irrelevant variables. It is classified in the paradigm of "magico-religious health" [28], which a person attributes the source of and solution to their disease on the mystical and supernatural power, not on organic bodily function and dynamics. Lewis et al. [29], for example, found that adults who are obese but still want to have a positive self-image about their health believe that they are allowed to expect a "magic cure" for changes in their health. Thus, agate stone loves may be among the people who have a high belief in such and deemed agate as their health solution.

Overall, the model seems to show an adequate fit to explain the fondness of arkenstone. Health Belief first plays a role in influencing Illusory Belief. In turn, Illusory Belief and Connectedness to Nature together influences Aesthetic Style. It means that in this context, the health belief of individual's with arkenstone influences them to view arkenstone as mystical, which combined with its natural origin, gives the stone a sense of aesthetic beauty to the possessor, making them fond of the stones.

The main impact of this study is of course to set a fundamental explanation regarding the current arkenstone trends, and possibly further similar trends that follow the same pattern. Knowing that the key is aesthetic style, we uncover the important reason of why the trend is so huge among Indonesian. Of course, aside from the theoretical discussion, an impact on a more practical level is on the economic 
Citation: Prayoga T, Abraham J (2016) Social-Psychological-Health Predictors of Fondness of Arkenstone among Indonesians. Abnorm Behav Psychol 2: 116. doi:10.4172/2472-0496.1000116

Page 5 of 5

growth. Since more beautiful stones are liked better, the industry has the potential to be expanded, such as through increasing the value of certain pattern, or create products that suit beautiful stone's pattern, opening up a possibility of a new mineral industry that is worth investing in Indonesia.

\section{Conclusion}

This is the first study to apply psychosocial factors in explaining the trend of arkenstone. We hypothesized that there were four factors underlying this trend: magical belief, aesthetic style, health belief, and connectedness with nature. Overall, our proposed model is able to significantly and thoroughly explain the phenomenon of arkenstone fever in Indonesia.

\section{Acknowledgement}

We would like to thank Frengky Johanes, Ezra Redo Jawentinus, and Virgon Hartoyo for their assistances in the initial phase of this research.

\section{References}

1. http://news.detik.com/berita/2864785/ikut-jadi-kolektor-akik-menteri-hanifakik-itu-budaya-nusantara

2. http://news.detik.com/berita/2866103/mensos-teliti-tingginya-gugat-cerai-dipurbalingga-bupati-batu-akik-jadi-solusi

3. HighBeam Research (2014) Research from Mashhad University of Medical Sciences reveals new findings on silicosis (Respiratory diseases in agate grinding workers in Iran). Respiratory Therapeutics Week.

4. Chen J (2009) The impact of aesthetics on attitudes towards websites. Usability.gov.

5. Ali M (2011) Aesthetics: An Introduction to the philosophy of art. Jakarta: Studio Luxor.

6. Godey B, Lagier J, Pederzoli D (2009) A measurement scale of 'aesthetic style' applied to luxury goods stores. International Journal of Retail and Distribution Management 37: 527-537.

7. Sugianto D (2015) Batu akik hitam pekat berkekuatan magis hadir di JFK Okezone.

8. Einstein DA, Menzies RG (2006) Magical thinking in obsessive-compulsive disorder, panic disorder and the general community. Behavioural and Cognitive Psychotherapy 34: 351-357.

9. Shihata S, Egan SJ, Rees CS (2014) Evaluation of magical thinking: Validation of the illusory beliefs inventory. Cognitive Behaviour Therapy 43: 251-261.

10. Subbotsky E (2004) Magical thinking in judgments of causation: Can anomalous phenomena affect ontological causal beliefs in children and adults? British Journal of Developmental Psychology 22: 123-152.

11. Yoshino D, Kimura A, Noguchi K (2009) Visual illusion and aesthetic preference: some common stimulus properties. Gestalt Theory 31: 29-42.

12. Cheng CK (2007) Understanding visual preferences for landscapes: an examination of the relationship between aesthetics and emotional bonding. Doctoral dissertation, Texas A and M University.

13. Dwijendra NKAA (2003) Perumahan dan permukiman tradisional Bali. Jurna Permukiman Natah 1: 8-24.

14. Olivos P, Aragonés Jl, Amérigo M (2011) The Connectedness with Nature Scale and its relationship with environmental beliefs and identity. International Journal of Hispanic Psychology 4: 5-19.
15. Brady $E$ (1998) Imagination and the aesthetic appreciation of nature. The Journal of Aesthetics and Art Criticism 56: 139-147.

16. Shalimar I (2015) Batu permata dan khasiatnya bagi kesehatan. Keluarga

17. Truter I (2006) Crystal healing and gem therapy: Using energy vibrations to heal and harmonise. SA Pharmaceutical Journal 73: 54-57.

18. Brunner E, Hiyoshi A, Cable N, Honjo K, Iso H (2012) Social epidemiology and Eastern wisdom. Journal of Epidemiology 22: 291-294.

19. Khalatbari J, Maddahi ME, Ghorbanshiroudi S, Keikhayfarzaneh MM (2013) Studying the relationship between illogical beliefs and general health among personals of Imam Sajjad Hospital in Ramsar Township. Procedia-Social and Behavioral Sciences 84: 1110-1113.

20. Jones CJ, Smith HE, Frew AJ, Toit GD, Mukhopadhyay S, et al. (2014) Explaining adherence to self-care behaviours amongst adolescents with food allergy: A comparison of the health belief model and the common sense selfregulation model. British Journal of Health Psychology 19: 65-82.

21. Butraporn P, Pach A, Pack RP, Masngarmmeung R, Maton T, et al. (2004) The health belief model and factors relating to potential use of a vaccine for Shigellosis in Kaeng Koi District, Saraburi Province, Thailand. J Health Popul Nutr 22: 170-181.

22. Bishop F, Yardley $L$ (2010) The development and initial validation of a new measure of lay definitions of health: The Wellness Beliefs Scale. Psychology and Health 25: 271-287.

23. Yung YF (2008) Structural equation modeling and path analysis using PROC TCALIS in SAS ${ }^{\circledR}$ 9.2. SAS Global Forum: Statistics and Data Analysis. pp: 1-19.

24. Carter M (2009) Response to Tavin's: The magical quality of aesthetics Studies in Art Education 50: 400-404

25. Kemp G (2007) Collingwood's aesthetics. Stanford Encyclopedia of Philosophy. 26. http://uknowledge.uky.edu/upk_dramatic_literature/5/

27. Paden R, Harmon L, Milling C (2012) Ecology, evolution, and aesthetics: Towards an evolutionary aesthetics of nature. The British Journal of Aesthetics 52: 123-139.

28. Andrews M, Boyle J (2008) Transcultural concepts in nursing care. Philadelphia: Wolters Kluwer Health/Lippincott Williams and Wilkins.

29. Lewis S, Thomas S, Blood R, Hyde J, Castle D, et al. (2010) Do health beliefs and behaviors differ according to severity of obesity? A qualitative study of Australian adults. Int J Environ Res Publ Health 7: 443-459. 